\title{
A study of endometrial RNA polymerase activity in infertile women
}

\author{
W. P. Soutter*, Hilda Allan $\dagger$, Sheila Cowan $\dagger$, T. C. Aitchison $\ddagger$ and \\ R. E. Leake ${ }^{\dagger}$ \\ *Department of Gynaecology, Western Infirmary, Glasgow G11 6NT, and \\ $\dagger$ Department of Biochemistry, and $\$$ Statistics, University of Glasgow, Glasgow G12 8QQ, U.K.
}

\begin{abstract}
Summary. Endometrial RNA polymerase activity, which is sensitive to oestrogens and progesterone, has been measured in normal and infertile patients. One-third of the infertile patients studied had abnormal values. An analysis of the relationship of abnormal RNA polymerase activity to clinical abnormalities and to pregnancies occurring without treatment suggests that this assay may detect a biochemical fault in the endometrium which is related to the failure to conceive.
\end{abstract}

\section{Introduction}

One of the commoner clinical problems in human infertility today is the infertile couple in whom no obvious physical or physiological abnormality can be found (Cooke et al., 1977). In such cases treatment can only be empirical, i.e. without any sound scientific basis, until the basic problem is identified. Borthwick \& Smellie (1975) have shown that one of the first responses of target tissues to a single dose of oestradiol is a transient increase in RNA polymerase B activity, followed by a sustained rise in RNA polymerase A activity. This early rise in RNA polymerase B activity is independent of RNA and protein synthesis, but that of RNA polymerase A activity is dependent upon both. The activities of the RNA polymerases might therefore provide an index of the sensitivity of the endometrium to plasma steroids. If infertility in some apparently normal patients is due to an abnormal response of the endometrium to normal plasma levels of oestradiol, this might be detected by an assay of endometrial RNA polymerase activities. We therefore studied the activities of the RNA polymerases in endometrial samples from a carefully defined group of normal, control patients and compared these with values for a population of infertile patients to determine whether abnormal values occurred in the infertile patients and whether they merely reflected a previously detected abnormality or indicated a separate pathology associated with persistent and otherwise unexplained infertility. An initial analysis of the data suggested that abnormal RNA polymerase results were found in patients with persistent, unexplained infertility. To ensure that valid comparisons were being made, subpopulations of the infertile patients were carefully defined, and the results in these reasonably homogenous groups analysed.

\section{Materials and Methods}

\section{Patients}

One sample of endometrium was obtained by curettage from each of 30 normal patients, mostly undergoing laparoscopic sterilization, who were chosen as controls because they satisfied the following criteria: (1) proven fertility; (2) a normal menstrual cycle (not more than 5 days of menstruation every 26-32 days with normal loss); (3) no steroid hormone treatment within the 
previous 6 months; (4) more than 6 months post partum; (5) at least one normal period since parturition; and (6) a histologically normal endometrium. Ovulation was not proven directly in each biopsy cycle in control patients except those from whom the biopsy was obtained in the luteal phase of the cycle when the endometrium showed histological evidence of secretory change compatible with the day of the cycle. However, all the control patients had proved their fertility by parturition and had regular menses, therefore the likelihood that the biopsy cycle may have been anovulatory was remote.

Sixty-three (63) patients complaining of infertility were also studied (see Table 1). Their male partners were referred to a urologist for examination and seminal analysis. Most of the patients initially underwent tubal insufflation and premenstrual endometrial biopsy. Ovulation was inferred from a histological appearance of the endometrium compatible with the assumed stage of the luteal phase at which it was obtained. In cases where doubt about the aetiology of the infertility remained, further evidence of ovulation was obtained, in all but one patient, from direct visualization of a corpus luteum at the time of laparoscopy, basal temperature charts, urinary pregnanediol levels (expressed per $10 \mathrm{~mm}$-creatinine) in an early morning sample of urine or from plasma progesterone levels in blood samples collected in the luteal phase of the cycle. If tubal blockage was suspected or if no cause for infertility was found in either partner, laparoscopy was performed. No patient was described as being free of clinical abnormality without confirmatory laparoscopy. On the basis of these investigations, the diagnosis of idiopathic infertility was made in 22 (Groups A, B, C, E) of the 63 'infertile' patients. Of these 22 patients infertility had lasted less than 5 years in 13 and $5(38 \%)$ of these 13 subsequently became pregnant without treatment. In contrast only $1(11 \%)$ out of 9 patients infertile for 5 or more years conceived without treatment. We therefore chose to define the 39 patients (of the total 63) that were infertile for 5 years or more as 'long-term infertile' patients, i.e. 8 from Group B, 1 from each of Groups C, D, H and J, 10 from each of Groups F and G, 4 from Group I and 3 from Group K.

\section{Tissue}

Endometrial samples obtained in the morning were divided immediately into two portions. One was put into formol saline for histology and the other into ice-cold sterile, buffered saline $(0.15 \mathrm{M}-\mathrm{NaCl}, 10 \mathrm{~mm}-\mathrm{Hepes}, \mathrm{pH} 7.4)$ for RNA polymerase assay.

Table 1. Clinical category and RNA polymerase ratio results in the 63 infertile patients

\begin{tabular}{|c|c|c|c|}
\hline \multirow[b]{2}{*}{ Group } & \multirow[b]{2}{*}{ Clinical category } & \multicolumn{2}{|c|}{ RNA polymerase ratio } \\
\hline & & Normal & Abnormal \\
\hline A & Unexplained continuing infertility ( $<5$ years) & 5 & r \\
\hline B & Unexplained continuing infertility $(>5$ years) & 2 & 6 \\
\hline $\mathrm{C}$ & Pregnancy occurring without treatment & 5 & 1 \\
\hline $\mathrm{D}$ & Pregnancy occurring after correction of a specific abnormality & 3 & 0 \\
\hline $\mathrm{E}$ & Pregnancy after empirical treatment & 1 & $1+1^{*}$ \\
\hline $\mathrm{F}$ & Bilateral tubal occlusion & 8 & 2 \\
\hline $\mathrm{G}$ & Unilateral tubal occlusion & 8 & 4 \\
\hline $\mathrm{H}$ & Anovulation & 2 & 1 \\
\hline I & Male infertility & 3 & 2 \\
\hline $\mathrm{J}$ & Endometriosis & 2 & 2 \\
\hline \multirow[t]{2}{*}{$\mathrm{K}$} & Miscellaneous (pelvic adhesions, hydronephrosis, cervical incompetence) & 3 & 1 \\
\hline & Total & 42 & 21 \\
\hline
\end{tabular}

* This patient also appears in Group B. 


\section{Preparation of nuclei}

Endometrium was homogenized in 10 volumes of $0.1 \%$ Triton X-100, $0.25 \mathrm{M}$-sucrose, 1.5

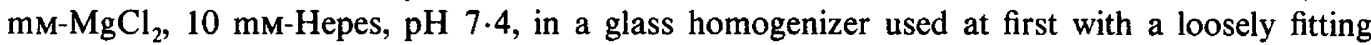
teflon pestle, and then with a tightly fitting pestle. The homogenization vessel was surrounded by ice throughout. Samples of the homogenate were examined by phase-contrast microscopy and homogenization was stopped when about $80 \%$ of nuclei were released because further homogenization only decreased the final yield of intact, active nuclei. The homogenate was centrifuged for $5 \mathrm{~min}$ at $700 \mathrm{~g}$, the supernatant was decanted and the nuclear pellet was washed twice in $0.25 \mathrm{M}$-sucrose, $1.5 \mathrm{mM}-\mathrm{MgCl}_{2}, 10 \mathrm{mM}$-Hepes, $\mathrm{pH} 7.4$, before being resuspended in $1 \mathrm{ml}$ assay buffer (250 mM-Tris-HCl, pH 7.9, $100 \mathrm{~mm}$-2-mercaptoethanol, $20 \%$ (v/v) glycerol). Optimum enzyme activity was achieved by processing the tissue at $\mathrm{pH} 7.4$ but carrying out the enzyme assay at 7.9 . Each preparation was examined by phase-contrast microscopy to confirm that it contained clean, intact endometrial nuclei free of any obvious contamination.

\section{Assay of RNA polymerase activity}

Each suspension of endometrial nuclei was assayed for RNA polymerase activity by the method described by Borthwick \& Smellie (1975). Briefly, RNA polymerase A activity was taken as the principal activity with reference to a zero time control measured in $4 \mathrm{~mm}-\mathrm{MgCl}_{2}$ in low ionic-strength buffer containing $\alpha$-amanitin, a specific inhibitor of RNA polymerase B. RNA polymerase $\mathrm{B}$ activity was taken as the $\alpha$-amanitin-sensitive portion of activity measured in 4 mM- $\mathrm{MnCl}_{2}$ at high ionic strength in which RNA polymerase A activity is minimal. RNA polymerase $\mathrm{C}$ activity is associated with the soluble fraction of endometrium fractionated in the above manner and therefore the activity due to RNA polymerase $\mathrm{C}$ in the nuclear fraction would be expected to be minimal.

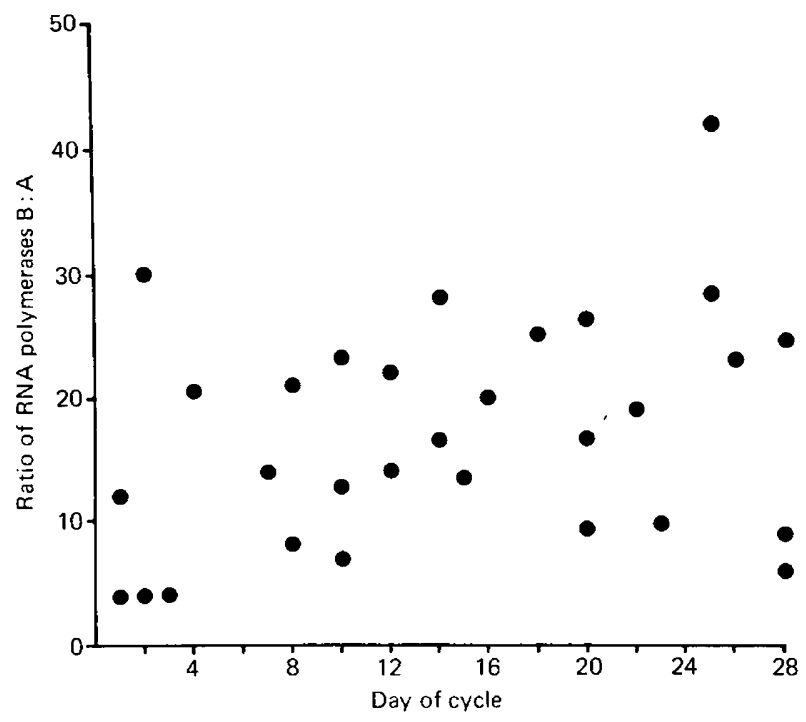

Text-fig. 1. The RNA polymerase ratios in clinically normal women (controls) throughout the menstrual cycle. A typical result gave an RNA polymerase A activity of 169 pmol $\left[{ }^{3} \mathrm{H}\right]$ UMP incorporated per mg DNA (341 c.p.m.) and an RNA polymerase B activity 1678 pmol [ $\left.{ }^{3} \mathrm{H}\right]$ UMP incorporated per mg DNA (3385 c.p.m.). 


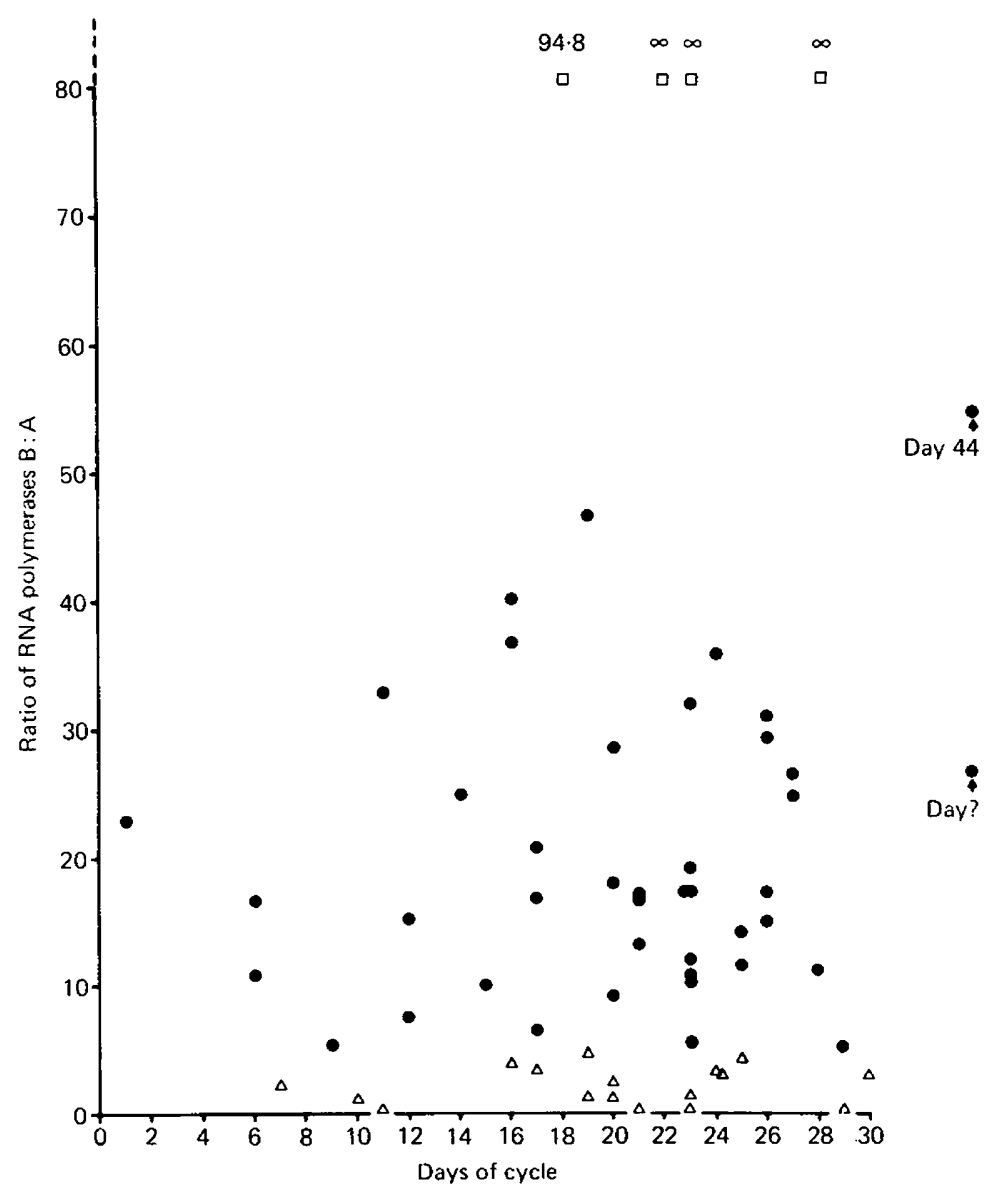

Text-fig. 2. The RNA polymerase ratios (e, normal; $\square$, high; $\Delta$, low) in 63 infertile patients. A typical result from a patient with a low ratio was $225 \mathrm{pmol}$ and $56 \mathrm{pmol}$ [ ${ }^{3} \mathrm{H}$ ]UMP incorporated per mg DNA (1128 and 284 c.p.m.) for RNA polymerases A and B respectively.

\section{Results}

To avoid problems of inter-patient variation the results were expressed as the ratio of RNA polymerase $B$ activity to that of RNA polymerase $A$. The ratios for the 30 control women ranged from 4 to 42 during the menstrual cycle, with no obvious cyclic pattern (Text-fig. 1). Values of 5-60 were designated as within the normal range. One-third of the 63 infertile patients had ratios outside the range of these control values ( 4 above and 17 below: Text-fig. 2). The average age of the control patients ( \pm s.d.) was $35.1 \pm 5.0$ years and was not significantly different from that of infertile patients with a normal ratio $(31.1 \pm 4.8$ years, $N=42)$, a low ratio $(31.5 \pm 3.2$ years, $N=17)$, or a high ratio $(31.8 \pm 5.9$ years, $N=4)$. The mean $( \pm$ s.d. $)$ RNA polymerase ratio of the control patients was $17.18 \pm 9.28$, this was not different from the mean value found in infertile patients with a normal ratio $(20.16 \pm 11.6)$ but both were clearly different from the mean value found in the 17 infertile patients with a low ratio $(2.38 \pm 1.56)$ and the high values found in the 4 infertile patients $(\infty, \infty, \infty$ and 94.8$)$.

Six infertile patients were examined on two different occasions: in 3 , a normal result was obtained on each occasion; in 2 , both results were abnormal; and one patient had a normal ratio after an initial low value. 
To determine whether abnormal RNA polymerase ratios indicate an endometrial defect likely to cause continuing unexplained infertility, the ratios in patients whose long-term infertility persisted despite no obvious explanation (Group B) were compared with those in 'long-term infertile' women who eventually did conceive or in whom an explanation for the infertility was found (1 from each of Groups C, D, H and J, 3 from Group K, 4 from Group I, 10 from Group $\mathrm{G}$ and all of Group F). Six (75\%) of the 8 Group B patients had abnormal RNA polymerase ratios, in contrast with only $9(29 \%)$ of the 31 patients who did conceive or who had an apparent clinical cause of their infertility $(P=0.025$, Fisher's Exact probability test).

These findings clearly suggest an association between persistent, unexplained infertility and abnormal RNA polymerase ratios. There were no differences between the groups in duration of infertility or of follow-up.

The incidence of normal and abnormal RNA polymerase ratios was also studied in 17 infertile patients who had no clinical abnormality, or in whom a specific abnormality had been corrected (hyperprolactinaemia, male partner pin-hole meatus, cervical incompetence, and who had no additional empirical treatment. All 17 were patients who, according to our conventional investigations, might have been expected to become pregnant, and who had had ample time to do so ( $>5$ years). Of the 9 patients who became pregnant (Groups $C$ and D) 8 had normal RNA polymerase ratios, in contrast to only 2 of the 8 who remained infertile for more than 5 years (Group B) ( $P=0.013$, Fisher's Exact probability test). The subsequent histories of the pregnancies were as follows: the patient with the abnormal polymerase ratio has safely delivered a normal child; 2 had spontaneous, histologically confirmed abortions (one was a blighted ovum), one patient emigrated at 17 week's gestation when her pregnancy was progressing satisfactorily, and the remaining 5 patients have completed uncomplicated pregnancies.

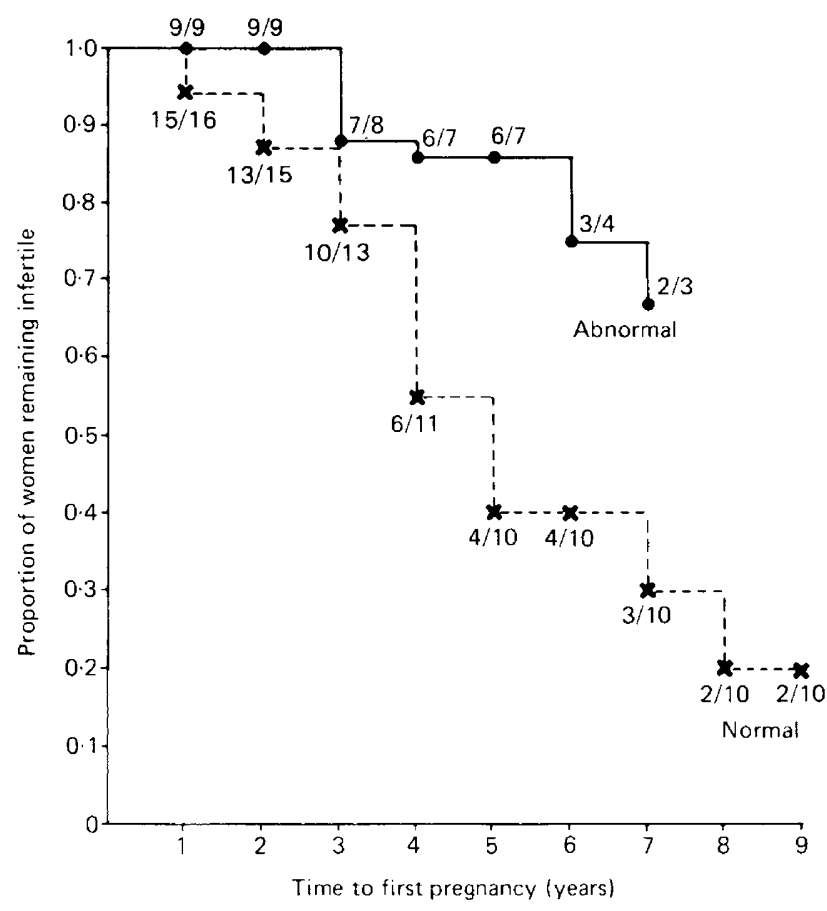

Text-fig. 3. The RNA polymerase ratio results and the cumulative proportions (e.g. 4/10) of patients who remained infertile with no clinical abnormality or a corrected abnormality and no empirical treatment. 
An actuarial method, described in the 'Appendix', was used to illustrate the occurrence of pregnancy in these 17 patients with normal and abnormal RNA polymerase ratios (Text-fig. 3 ). The data for 8 other patients infertile for less than 5 years are included (Groups A and E) and the duration of untreated infertility of each woman is taken into account. This analysis shows that the likelihood of pregnancy occurring in patients with an abnormal RNA polymerase ratio without some form of effective treatment is less than in those with a normal ratio value $(P<$ $0 \cdot 05)$.

Three patients (Group E plus 1 patient from Group B) became pregnant after empirical treatment when no specific, conventionally accepted abnormality had been detected. One patient with a normal RNA polymerase ratio (17.7) had been infertile for 3 years. A premenstrual endometrial biopsy was taken on two occasions; both samples were reported as being consistent with her menstrual history and a recently ruptured corpus luteum was seen at laparoscopy. In spite of these findings, 2 months later a regimen of $50 \mathrm{mg}$ clomiphene citrate (Merrell) daily from Days 5-10 of the cycle was prescribed and twins were conceived during the first treatment cycle. A patient with a borderline low RNA polymerase ratio (3.6), who had been infertile for 7 years in spite of apparently satisfactory tests of reproductive function, achieved a successful pregnancy following a weekly injection of 500 i.u. hCG (Pregnyl: Organon) for 6 weeks. A patient with a high RNA polymerase ratio $(\infty)$, who had been infertile for 4 years appeared to be normal in every respect except for slightly low serial plasma oestrogen measurements, was given $100 \mathrm{mg}$ clomiphene daily for Days 5-10 of the cycle. The RNA polymerase ratio remained high but the plasma oestrogen and progesterone values rose markedly and she conceived during her 5 th cycle of treatment.

One patient (Group J), who had discontinued oral contraception $2 \frac{1}{2}$ years before these investigations was found to have very early endometriosis in the Pouch of Douglas but a recently-formed corpus luteum and a secretory endometrium compatible with her menstrual history. The RNA polymerase ratio was low $(0 \cdot 25)$. Although there was no evidence that the endometriosis was affecting reproductive function, she was given Danazol (Winthrop) orally $(200 \mathrm{mg} / 8 \mathrm{~h}$ ) for 5 months followed by 2 injections of $250 \mathrm{mg}$ medroxyprogesterone 6 weeks apart to ablate this early disease: conception occurred 9 months later without further investigation or treatment.

Only one patient (Group C) with a low RNA polymerase ratio $(0.64)$ became pregnant without treatment, doing so 3 months after the assay. She had stopped taking oral contraceptives 3 years previously.

It was possible that the RNA polymerase ratio was abnormal in these apparently normal infertile patients because they had undetected anovulation. However, only 3 of the 63 patients described in Table 1 and 2 further patients, whose results have become available since the statistical analysis was performed, were found to be anovulatory. The first of these patients had primary amenorrhoea, non-secretory endometrium and inactive ovaries at laparoscopy but the RNA polymerase ratio was normal $(26 \cdot 6)$. The second had had primary amenorrhoea until 38 years of age when she began to menstruate irregularly; the endometrium was non-secretory, her urinary steroid excretion reflected the anovulation but the RNA polymerase ratio was normal (7.5). A patient with secondary amenorrhoea after anorexia nervosa had a non-secretory endometrium but a normal RNA polymerase ratio (10.5). Another patient with secondary amenorrhoea (following cessation of the oral contraceptive pill) was found to have secretory endometrium on Day 44 of her cycle but no corpus luteum was seen at laparoscopy performed at the same time and subsequent urinary steroid excretion suggested anovulation; the RNA polymerase ratio was normal (55.4). Finally, a patient with regular menses, who had undergone laparoscopic examination elsewhere and been diagnosed as anovulatory from urinary steroid excretion, was found to have a hyperplastic, non-secretory endometrium on Day 20 of the cycle and a low (2.8) RNA polymerase ratio. Of these 5 patients known to be anovulatory, therefore, 4 had a normal RNA polymerase ratio. 


\section{Discussion}

The association between an abnormal RNA polymerase ratio and persistent, unexplained infertility demonstrated by this study suggests that the endometrial RNA polymerase assay may indicate the presence of a primary molecular cause for infertility that is not apparent by histological examination. Patients who remain infertile without an apparent clinical abnormality and with a normal RNA polymerase ratio may well have another undetected disorder. Those who have an abnormal ratio and another apparent explanation for their infertility have, in many cases, only a minor clinical abnormality and the RNA polymerase ratio may indicate the true nature of their problems. The 4 normal pregnancies that occurred in women with low ratios suggest that the endometrial defect is not irremediable. In some cases it might revert to normal spontaneously, particularly if it resulted from oral contraception (see below). In other cases the defect may be corrected or bypassed in some way by treatment.

We have frequently found abnormal RNA polymerase ratios in association with current or recent oral contraception. The delay in conception which appears to follow oral contraceptive usage (Royal College of General Practitioners, 1974; Vessey, Wright, McPherson \& Wiggins, 1977) might well be explained by the persistence of such an abnormality. Misleading results might then be obtained from this assay in patients in whom the RNA polymerase abnormality is a sequel to oral contraception and who subsequently conceive if the endometrial cells recover spontaneously. Another potential source of error is endometrium obtained from the isthmus of the uterus. This is usually relatively inactive and would be expected to give abnormal levels of RNA polymerase activity. Therefore, although each endometrial specimen was carefully divided into two adjacent portions, the possibility cannot be completely ruled out that, although the tissue sent for microscopic examination was histologically normal, some inactive tissue may have been included in the sample for RNA polymerase assay.

It would be surprising if some cases of infertility were not due to abnormalities in the endometrium too subtle to give rise to morphological changes detectable by light microscopy. This study suggests that one such abnormality may be detected by assay of RNA polymerase activities in the nuclei of endometrial cells.

We thank the medical and theatre staff of the Gynaecology Department in the Western Infirmary for their wholehearted help and co-operation, Professor C. R. Whitfield for his advice and help in the preparation of the manuscript, and Professor R. M. S. Smellie for provision of laboratory space and facilities.

\section{Appendix}

For a given RNA polymerase ratio, $R$ (whether normal or abnormal), let $\rho_{\mathrm{R}}$ be the proportion of 'truly' infertile women in the population of all 'reporting' infertile women with this result. Assume that the time taken by any fertile woman to become pregnant is not influenced by her test result and that the distribution of times to pregnancy can be adequately represented by an exponential model (exp) with the expected time until pregnancy of $\theta$. Then the probability $(P)$ of a woman not having had her first pregnancy by $t$ years, given a test result of $\mathrm{R}$ is:

$$
\begin{aligned}
& P\left(\begin{array}{c|c}
\text { not pregnant } & \text { woman } \\
\text { within } t \text { years } & \begin{array}{c}
\text { fertile }
\end{array}
\end{array}\right) P\left(\begin{array}{c}
\text { woman } \\
\text { fertile }
\end{array} \mid \mathrm{R}\right) \\
& +P\left(\begin{array}{c|c}
\text { not pregnant } & \text { woman } \\
\text { within } t \text { years } & \text { infertile }
\end{array}\right) P\left(\begin{array}{c|c}
\text { woman } \\
\text { infertile }
\end{array} \mid \mathrm{R}\right) \\
& =\exp \left(\frac{t}{\theta}\right)\left(1-\rho_{\mathrm{R}}\right)+1 \times \rho_{\mathrm{R}}
\end{aligned}
$$

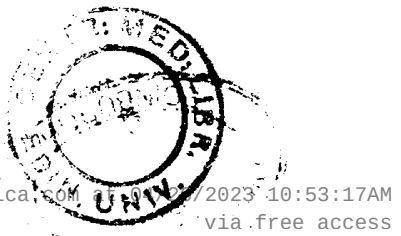


Similarly, the probability of becoming pregnant at time $t$ is:

$$
\frac{\exp (-t / \theta)}{\theta}\left(1-\rho_{\mathrm{R}}\right)+0 \times \rho_{\mathrm{R}}
$$

For this model maximum likelihood estimates (see Kendall \& Stuart, 1961) were:

$$
\hat{\rho}_{\mathrm{A}}=0.75 ; \quad \hat{\rho}_{\mathrm{N}}=0 ; \quad \hat{\theta}=8.4 \text { years. }
$$

If we assume that all the patients are from the same population and that the test result is irrelevant then we obtain:

$$
\hat{\rho}_{\mathrm{A}}=\hat{\rho}_{\mathrm{N}}=0 ; \quad \hat{\theta}=12 \cdot 3 \text { years. }
$$

A likelihood ratio test (see Kendall \& Stuart, 1961) that $\rho_{\mathrm{A}}=\rho_{\mathrm{N}}$ against $\rho_{\mathrm{A}} \neq \rho_{\mathrm{N}}$ gives an observed value of the test statistic of 3.54. If $\rho_{\mathrm{A}}=\rho_{\mathrm{N}}$, this should be an observation from a distribution which is approximately $\chi^{2}$ with 1 d.f. As the upper $5 \%$ point of such a distribution is 3.84 , we cannot quite reject the hypothesis that the test result is irrelevant with respect to infertility but the obvious implication from the data is that the proportion of 'truly' infertile patients with a normal RNA polymerase ratio is much less than that with an abnormal ratio.

A similar analysis using the slightly more complicated assumption that the times to pregnancy follow a log-normal distribution does provide a significant result at $5 \%$ and thus emphasizes that a difference in the proportions of 'truly infertile' patients among those with normal and abnormal RNA polymerase ratios does exist. The log-normal assumption leaves the estimates of $\rho_{\mathrm{A}}$ and $\rho_{\mathrm{N}}$ unaltered but provides a better fit on those who become pregnant.

\section{References}

Borthwick, N.M. \& Smellie, R.M.S. (1975) The effects of oestradiol- $17 \beta$ on the ribonucleic acid polymerases of immature rabbit uterus. Biochem. J. 147, 91-101.

Cooke, I.D., Lenton, E.A., Adams, M., Pearce, M.A., Fahmy, D. \& Evans, C.R. (1977) Some clinical aspects of pituitary-ovarian relationships in women with ovulatory infertility. J. Reprod. Fert. 51, 203213.
Kendall, M.G. \& Stuart, A. (Eds) (1961) The Advanced Theory of Statistics, Vol. 2. Griffin \& Co., London.

Royal College of General Practitioners (1974) Oral Contraceptives and Health, pp. 74-77. Pitman Medical, London.

Vessey, M.P., Wright, N.H., McPherson, K. \& Wiggins, P. (1978) Fertility after stopping different methods of contraception. Br. med.J. 1, 265-267.

Received 4 April 1978 